\title{
Danon Disease in an Asymptomatic Woman: A Five-Year Follow Up
}

\author{
Ricardo Cardoso Cardoso de Matos, ${ }^{1(1)}$ Amanda Cunha Soares, ${ }^{1,2}{ }^{(1)}$ Raquel Tavares Boy da Silva, ${ }^{3(0)}$ Evandro Tinoco \\ Mesquita ${ }^{1,4,5} \mathbb{D}$ \\ Universidade Federal Fluminense (UFF-HUAP), ${ }^{1}$ Niterói, RJ - Brazil \\ Unigranrio Caxias, ${ }^{2}$ Duque de Caxias, $R J$ - Brazil \\ Universidade do Estado do Rio de Janeiro (UERJ-HUPE), ${ }^{3}$ Rio de Janeiro, $R J$ - Brazil \\ Complexo Hospitalar de Niterói, ${ }^{4}$ Niterói, $R J$ - Brazil \\ Pró-cardíaco Hospital, ${ }^{5}$ Rio de Janeiro, $R J$ - Brazil
}

\section{Introdução}

Danon disease $(\mathrm{DD})^{1}$ is a rare, dominant $\mathrm{X}$-linked disease caused by mutation of the LAMP2 gene, which encodes a lysosome-associated membrane glycoprotein, thereby affecting lysosomal deposition. DD is characterized by a classic triad of cardiomyopathy (featured by hypertrophic cardiomyopathy $[\mathrm{HC}]$ ), skeletal myopathy, and cognitive changes. While female patients tend to have milder phenotypic manifestations, an isolated cardiac involvement, in addition to a later onset of symptoms, without the need for heart transplantation before the fourth decade of life, male patients commonly have the presentation of the classic triad of disease. ${ }^{2}$

The clues of the involvement of HC with preexcitation and persistent increased troponin I in these individuals are related to the process of autophagy that contributes to cardiac remodeling. ${ }^{3}$ However, there is still no specific treatment for DD. The approach to cardiac manifestations includes implantable cardioverter defibrillator (ICD) and ablation to improve symptoms and decrease the risk of sudden death. In cases of advanced heart failure (HF), heart transplantation is an effective and safe measure. Studies for gene therapy are currently in progress. ${ }^{4,5}$

\section{Keywords}

Glycogen Storage Disease Type II/genetics; Cardiomyopathy Hypertrophic; Phenotype; LysosomalAssoiated Membrane Protein 2/genetics (DD Danon Disease).
Considering the small number of cases described in the literature about DD and the gap in knowledge for an earlier approach, we aimed to describe the case of a patient with incidental diagnosis of $\mathrm{DD}$, presenting a mutation not previously described in the literature and its five-year follow-up.

\section{Case description}

A female 23-year-old Caucasian patient, only daughter of a no consaguineous couple, was incidentally diagnosed with $\mathrm{HC}$ at 18 years of age during the preoperative period of an orthopedic surgery and confirmed by cardiac resonance. The parents were asymptomatic, with normal echocardiogram.

At the age of 20, she was admitted to the emergency department with atypical chest pain, and no other findings at physical examination, and laboratory tests showed an increase in troponin I (6ng/dL). She underwent a new cardiac magnetic resonance imaging confirming the diagnosis of $\mathrm{CH}$ with delayed gadolinium enhancement (Figure 1). At the time, she was diagnosed with acute myocarditis.

Patient was referred to a specialized HF center, where a Doppler echocardiography was performed, confirming the findings of HC (Figure 2), and revealing slight obstruction of the outflow pathway, and a Wolff-Parkinson-White (WPW) preexcitation pattern. The patient had elevated and stable levels of troponin I (7.74ng/dL), and natriuretic peptide (BNP) levels of $401 \mathrm{pg} / \mathrm{mL}$ six months after admission for chest pain. The patient underwent genetic testing; a new mutation NP_002285.1:p.Asn242Thrfs ${ }^{*} 41$ compatible with DD was identified, and referred as accessory pathway (VA) ablation due to the WPW-type preexcitation.

Mailing Address: Ricardo Cardoso de Matos

Universidade Federal Fluminense - Hospital Universitário Antônio Pedro, Departamento de Medicina Interna

Avenida Marques do Paraná, 303. Postal Code: 24033-900, Niterói, RJ - Brazil

E-mail: ricardocardoso2310@gmail.com 


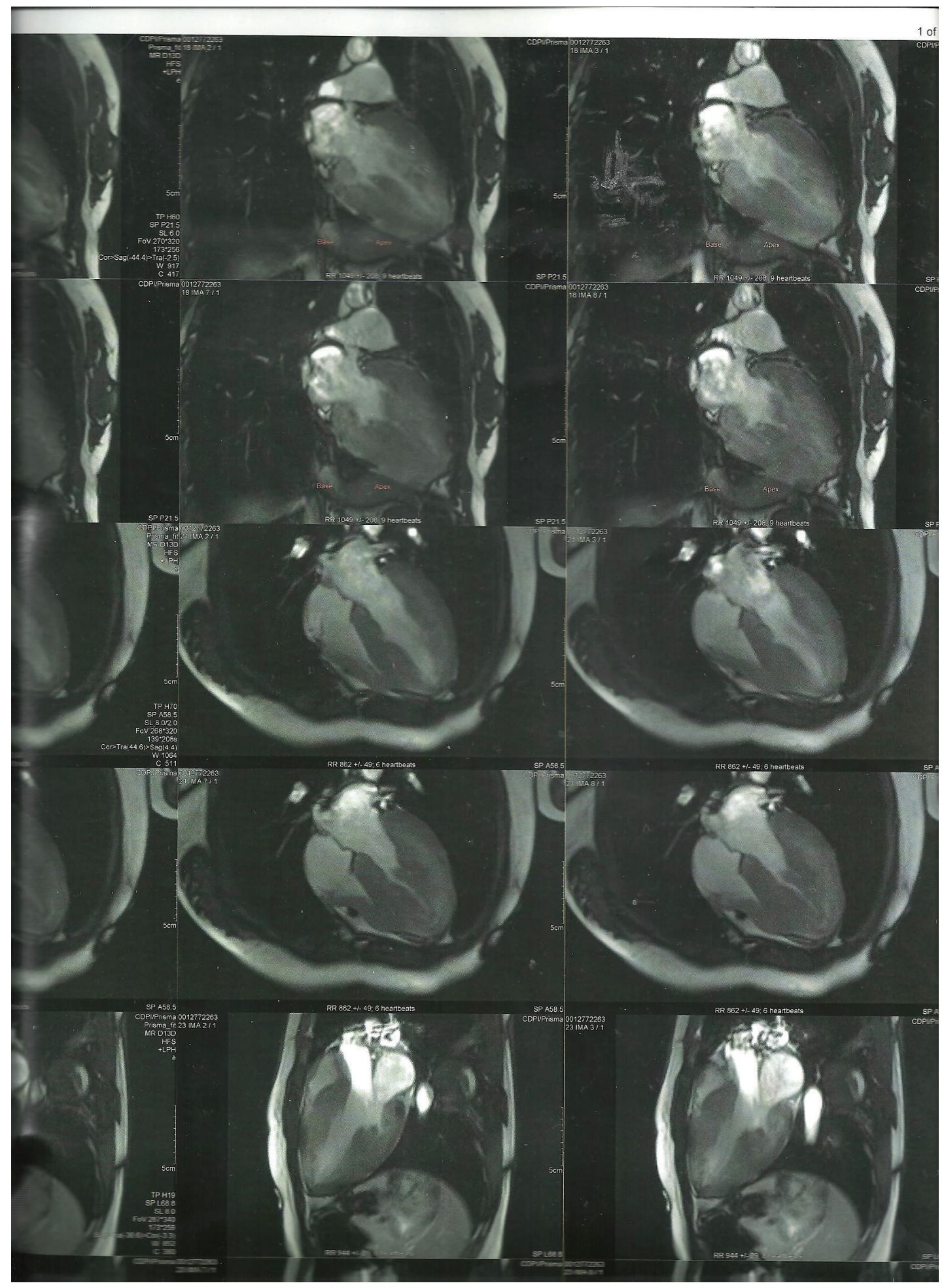

Figure 1 - Gadolinium-enhanced cardiac magnetic resonance imaging showing left ventricular hypertrophy with involvement of apical segments and mid-basal portion of the anterior and lateral walls and left ventricular diastolic dysfunction, suggestive of myocardial fibrosis observed in cases of hypertrophic cardiomyopathy. Left ventricular ejection fraction: $78 \%$. Maximum end diastolic thickness of septum IV $=2.1 \mathrm{~cm}$; lateral wall $=2.0 \mathrm{~cm}$. 

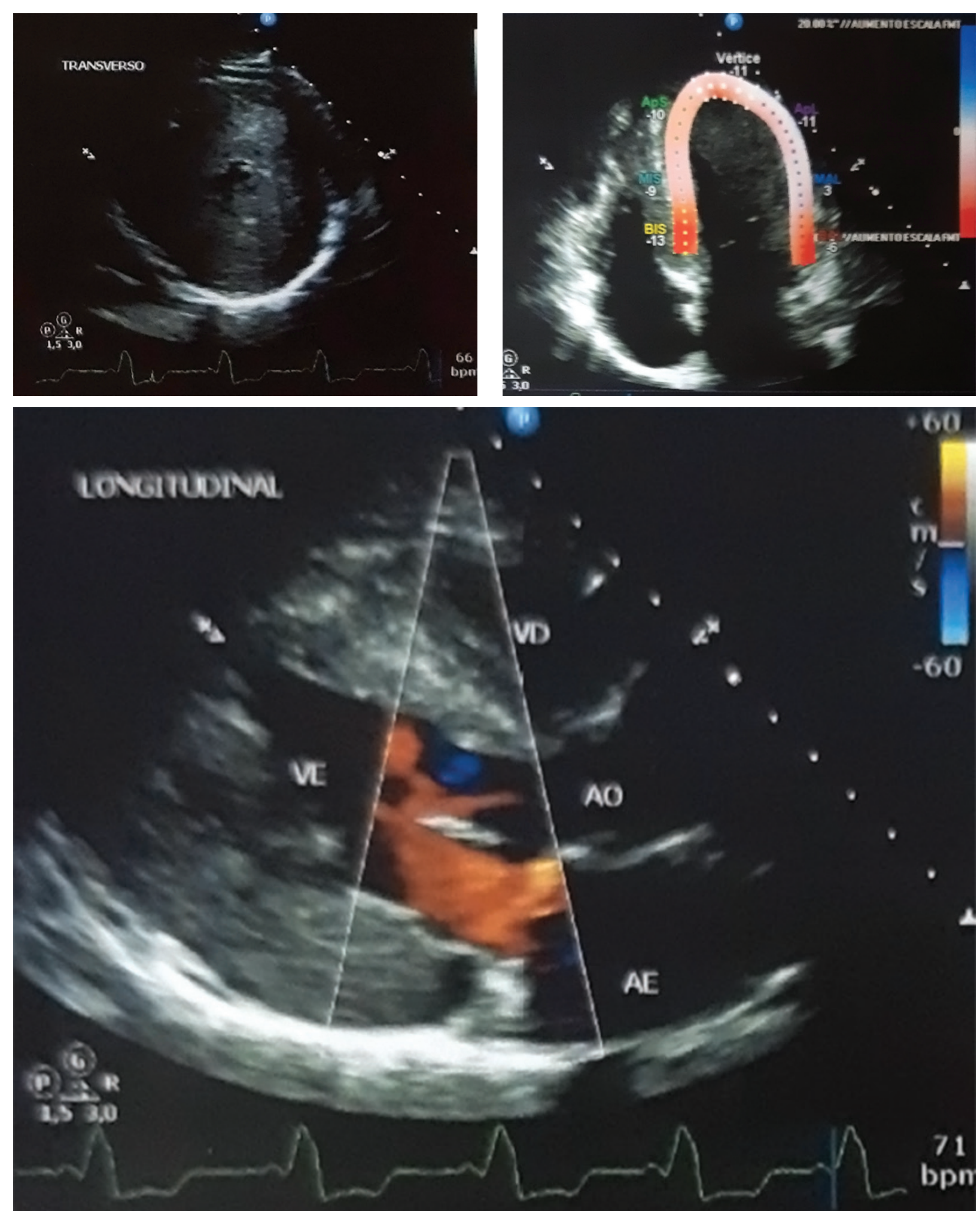

Figure 2 - Doppler echocardiogram showing alteration of left ventricular diastolic function and hypertrophic cardiomyopathy 
After three months, the patient presented with a new WPW-compatible pre-excitation episode involving the same VA, and referred for another ablation. A followup Holter revealed an asymptomatic, non-sustained ventricular tachycardia (VT) (Figure 3), and an implantable cardioverter defibrillator (ICD) was indicated, based on the cardiac resonance imaging findings also.

Since then, the patient has been asymptomatic, undergoing cardiac rehabilitation and treatment with beta-blockers. There has been no ICD firing since its implantation, in addition to normal renal, hepatic, ophthalmic and neurological functional tests. The patient has been followed by the departments of clinical genetics, cardiology, and arrhythmology, and received psychological support for anxiety disorder. In the last months she has been in isolation due to the COVID-19 pandemic and routinely performed physical activities and in telemedicine consultation. The temporal progression of the events were described in Tablet 1.

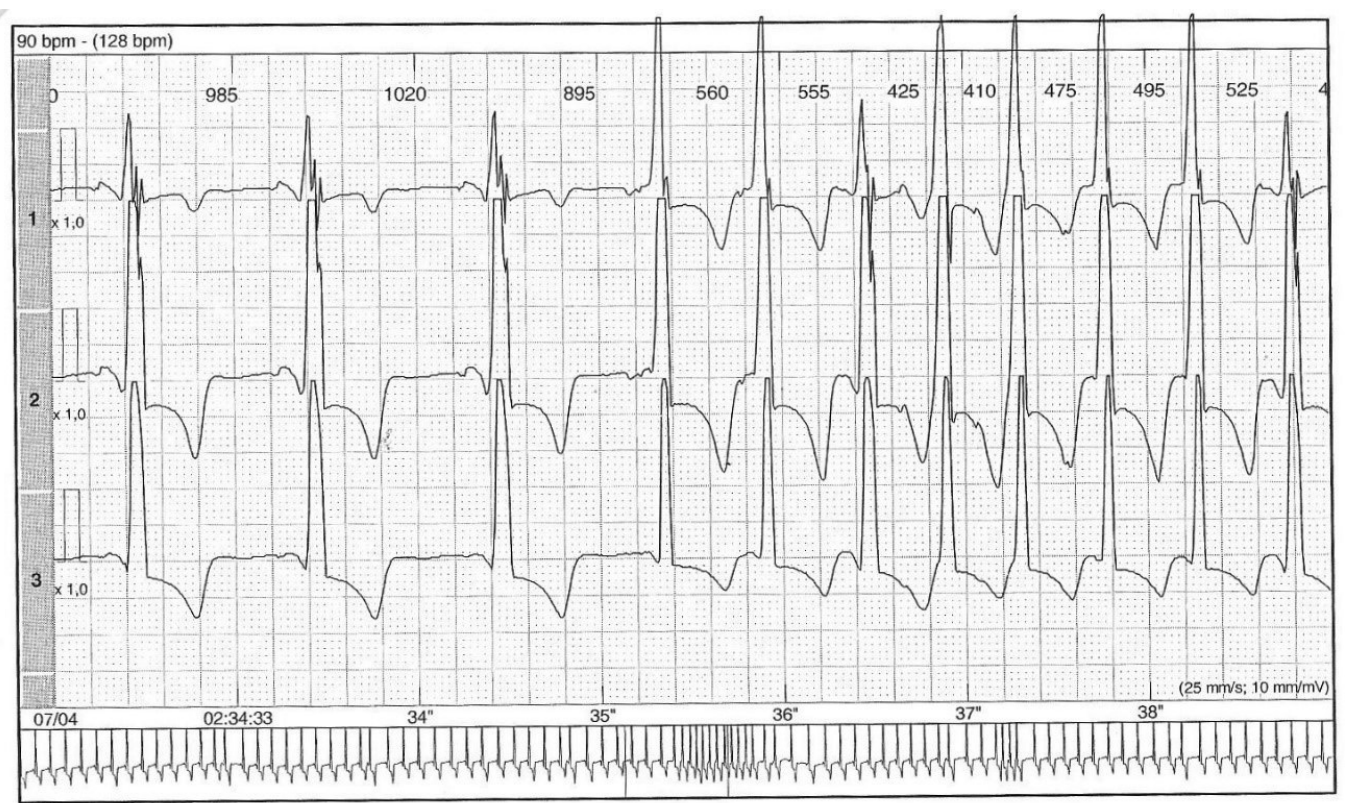

Figure 3 - Electrocardiogram showing non-sustained ventricular tachycardia.

Table 1 - Table describing the temporal progression of events

\begin{tabular}{|c|c|}
\hline Temporal Evolution & Events \\
\hline $\begin{array}{l}2014 \\
18 \text { years old }\end{array}$ & Diagnosis of hypertrophic cardiomyopathy during the preoperative evaluation for orthopedic surgery. \\
\hline $\begin{array}{l}2016 \\
20 \text { years old }\end{array}$ & $\begin{array}{l}\text { Patient admitted for atypical chest pain. The patient was referred to a specialized cardiac failure service that } \\
\text { identified in 12-lead ECG the presence of Wolff-Parkinson-White preexcitation pattern. }\end{array}$ \\
\hline $\begin{array}{l}2017 \\
21 \text { years old }\end{array}$ & $\begin{array}{l}\text { Patient seeks the emergency for the second time with complaint of palpitation; she was diagnosed with Wolff- } \\
\text { Parkinson-White pre-excitation and referred to first ablation. }\end{array}$ \\
\hline $\begin{array}{l}2018 \\
22 \text { years old }\end{array}$ & $\begin{array}{l}\text { After the insertion of the Holter track, several episodes of non-sustained ventricular tachycardia (VT) were } \\
\text { observed. The patient was referred for implantable cardioverter defibrillator placement. }\end{array}$ \\
\hline $\begin{array}{l}2019 \\
23 \text { years old }\end{array}$ & $\begin{array}{l}\text { The patient remains asymptomatic, undergoing multidisciplinary follow-up and cardiac rehabilitation three times } \\
\text { a week. In the last months she has been in isolation due to the COVID-19 pandemic and routinely performing } \\
\text { physical activities and in telemedicine consultation. }\end{array}$ \\
\hline
\end{tabular}




\section{Discussion}

The present study reports the case of late diagnosis of $\mathrm{DD}$ as the cause of $\mathrm{HC}$, with a new genetic variant in heterozygosis NP_002285.1:p.Asn242Thrfs*41 in the LAMP2 protein encoding the protein Lysosome-associated membrane glycoprotein 2 . This variant of the truncating frameshift mutation has not been previously published, or even identified in controls. No truncating variant of this gene is listed in the database Exome Aggregated Consortium (ExAC). The consequence of this mutation is the creation of a stop codon that causes a premature interruption in the coding of the LAMP2B protein.,

Biological diagnosis of DD involves demonstration of normal or high acid maltase activity in combination with muscle biopsies showing large vacuoles filled with glycogen, cytoplasmic degradation products and partial or total absence of LAMP-2 protein in immunohistochemical analysis. ${ }^{1,8}$ Thus, the diagnosis can be confirmed by molecular analysis of the LAMP2 gene and evaluation of the three isoforms: LAMP 2A, LAMP 2B and LAMP 2C. The LAMP 2B isoform is responsible for metabolic defects, impairing autophagosome-lysosome fusion, leading to heart disease in DD. ${ }^{7}$

The Wolff-Parkinson-White syndrome is an important diagnosis, especially in women. ${ }^{9}$. This finding culminated in the indication of the first ablation of the anomalous pathway. In a recent systematic review evaluating 146 patients with DD, while female patients had a predominant pattern of cardiomyopathy alone, as presented in our case report, men more commonly presented the clinical triad of HC, skeletal myopathy and mental illnesses. ${ }^{9}$

In addition, the reported case had chest pain accompanied by elevated troponin I levels, which raised the suspicion of acute myocarditis. Later, the persistence of elevated troponin levels over the months indicated a false diagnosis of myocarditis. Cardiac resonance has allowed a more accurate evaluation of the site of myocardial hypertrophy, presence of intracavitary thrombi, and recently, presence of fibrosis, which is an important prognostic marker in this group of patients. Myocardial injury and increased troponin may cause myocardial remodeling and explain the progression to a dilated form of myocardiopathy. High levels of troponin I in DD has prognostic value in the clinical decisionmaking process. ${ }^{10}$
A recent clinical trial ${ }^{5}$ studied gene therapy in male patients with DD. This therapy involves a recombinant adeno-associated virus containing the transgene isoform LAMP2B (RP-A501), which will contribute to a better management and understanding of the disease. ${ }^{5}$

\section{Danon Disease}

Danon disease is an uncommon condition, and rarely recognized as a red flag for $\mathrm{CH}$ phenocopying. Because there was no specific treatment during the follow-up of the patient reported in this study, several interventions and hospitalizations were necessary over the five years of follow-up. This shows the importance of cardiac surveillance and multidisciplinary approach of this group of patients. Also, telemedicine support allows the maintenance of care despite the COVID-19 pandemic. Finally, genetic testing should be incorporated into clinical practice for congenital heart disease.

\section{Potential Conflict of Interest}

No potential conflict of interest relevant to this article was reported.

\section{Sources of Funding}

There were no external funding sources for this study.

\section{Study Association}

This study is not associated with any thesis or dissertation work.

\section{Ethics approval and consent to participate}

This article does not contain any studies with human participants or animals performed by any of the authors.

\section{Author contributions}

Conception and design of the research: Matos RC, Soares AC, Silva RTB, Mesquita ET. Acquisition of data: Matos RC, Soares AC, Silva RTB, Mesquita ET. Analysis and interpretation of the data: Matos RC, Soares AC, Silva RTB, Mesquita ET. Writing of the manuscript: Matos RC, Soares AC, Mesquita ET. Critical revision of the manuscript for intellectual content: Mesquita ET. 


\section{References}

1. Nishino I, Fu J, Tanju K, Yamada T, Shimojo S, Koori T, et al. Primary LAMP-2 deficiency causes X-linked vacuolar cardiomyopathy and myopathy (Danon Disease); Nature .2000;406(6798):906-10.

2. Brambatti M, Caspi O, Maolo A, koshi E, Greenberg S, Taylor M, et al. Danon desease: gender diferences in presentation and outcomes. Int J Cardiol. 2019. doi:101016/j.ijcard.

3. Fu L, Luo S, Cai S, Hong W, Guo Y, Wu J et al. Identification of LAMP2 mutations in early-onset Danon disease with hypertrophic cardiomyopathy by targeted next-generation sequencing. Am J Cardiol. 2016;118:888-94.

4. Samad F, Jain R, Jan MF, Sulemanjee NZ, Minaria P, Kalvin L, et al. Malignant cardiac phenotypic expression of Danon disease (LAMP2 cardiomyopathy). Int J Cardiol. 2017; 245:201.

5. Cenacchi G, Papa V, Pegoraro V, Marozzo , Fanin M, Angelini C. Danon disease: review of natural histry and recent advances. Neuropathol Appl Neurobiol 219; 46(4):303-22. doi:10.1111/nan.12587
6. ClinVar: Landrum MJ, Lee JM, Riley GR, Jang W, Rubinstein WS, Church DM,et al. ClinVar: public archive of relationships among sequence variation and human phenotype. Nucleic Acids Res. 2014 Jan 1;42(1):D980-5. doi:10.1093/nar/gkt1113.

7. Takahashi M, Yamamoto A, Takano K, Sudo A Takahito Wada $\mathrm{T}$, et al. Germline mosaicism of a novel mutation in lysosomeassociated membrane protein-2 deficiency (Danon disease). Ann Neurol.2002;52(1):122.

8. Danon MJ, Oh SJ, DiMauro S, Maligod JR, Eastwood A, Naidu S, et al. Lysosomal glycogen storage disease with normal acid maltase. Neurology. 1981; 31(1):51-7.

9. D'souza RS, Levandowski C, Slavov D, Graw SL, Allen L.A, Adler E.et al. Danon disease: clinical features, evaluation, and management. Circ Heart Fail. 2014;7(5):843-9.

10. Roos JCP, Daniels MJ, Morris E, Hyry HI, Cox T.M. Heterogeneity in a large pedigree with Danon disease: Implications for pathogenesis and management. Mol Genet Metab. 2018;123(2):177-83. 